\title{
Arte e sociedade no Brasil e em Portugal no final do séc. XIX pelas trajetórias dos pintores Almeida Júnior e José Malhoa

\author{
Weslei Estradiote Rodrigues ${ }^{7}$
} \\ DOI 10.20396/eha.vil4.3424
}

A proposta de aproximar analítica e comparativamente os universos artísticos do Brasil e de Portugal do século XIX não é inédita. Na verdade, os nexos históricos e lógicos possíveis entre esses dois contextos nacionais já foram apontados significativamente por diversos autores². $\mathrm{E}$ tal como sugerem, mais do que produzir algumas aproximações ou paralelismos, pensar a arte nesses dois países nesse exato contexto implica relacioná-los. Ou seja, havia uma significativa circulação de agentes e ideias entre os dois países que configurava uma rede extensa de relações e correlações.

Vale notar, no entanto, que essa circulação se fazia prioritariamente no sentido de Portugal para o Brasil. A recíproca não era equivalente. Enquanto contam-se numerosas exposições portuguesas no Brasil, sobretudo no Rio de Janeiro, as incursões de artistas brasileiros por Portugal são bastante mais raras, para não dizer inexistentes ${ }^{3}$. Desde pelo menos o final da década de 1870 podemos listar a exposição de produtos portugueses em solo brasileiro que contou com uma seção de belas artes. Foram comuns também as participações de artistas portugueses nas exposições gerais da Academia Imperial de Belas-Artes (AIBA) do Rio de Janeiro, e ao longo das duas primeiras décadas do século XX foram diversas as exposições individuais de artistas portugueses no Brasil. Isso tudo sem ainda mencionar a notória circulação de críticos portugueses pelo Brasil, e os periódicos produzidos e idealizados por lá e aqui vendidos.

Claro que essa tendência tem a ver com a condição histórica da cada país no quadro geral do período. Ex-colônia recém independente, em termos especificamente artísticos o Brasil possuía menor acúmulo institucional. Muito embora as academias dos dois países tenham sido fundadas em datas muito próximas (a AIBA ligeiramente mais antiga, inclusive), Portugal contava desde o final do século XVIII com meios institucionalizados (embora precários) de formação e amparo de artistas. É preciso destacar nesse âmbito a Academia de Portugal em Roma, por exemplo, que rece-

\footnotetext{
1 Doutorando em Sociologia e Mestre em Antropologia Social pela Universidade de São Paulo (USP). Bolsista do Conselho Nacional de Desenvolvimento Científico e Tecnológico (CNPq).E-mail: weslei.rodrigues@usp.br 2 A esse respeito ver Migliaccio (2001 e 2014), Silva (2019), Valle (2012 e 2015) e Pitta (2013: 73).

3 Entre os raros exemplos, vale lembrar a viagem de Antônio Parreiras em 1906 e a ousada tentativa de Oscar Pereira da Silva, já em 1914.
} 
bia e orientava alunos bolsistas portugueses na Itália até por volta da década de 1830. Por sua vez, o reconhecimento do Brasil como nação e o início de suas trocas e trânsitos artísticos transnacionais se acentuaram um tanto mais tardiamente, já sob o manto do mecenato imperial de D. Pedro II.

No entanto, a despeito das disparidades entre os dois países no campo específico da arte nesse exato período, o que mais marca e justifica a quase unidirecionalidade dos trânsitos artísticos é a presença da imigração portuguesa no Rio de Janeiro. O grande contingente de imigrantes portugueses endinheirados no Brasil e sua relevância política na estrutura econômica e burocrática do Rio de Janeiro tornavam-no um mercado especialmente interessante para os artistas portugueses. Essa elite portuguesa que se perpetuou após a independência criou no Rio de Janeiro uma ampla estrutura institucional de promoção à arte, à literatura e de acolhimento ao contingente migrante que continuava chegando em número cada vez maior. Exemplos salutares dessa estrutura são a Sociedade Portuguesa de Beneficência (1840), o Real Gabinete Português de Leitura (1837), bem como algumas associações desportivas ${ }^{4}$.

Em resumo, o Brasil era um mercado frutífero para os artistas portugueses, mas Portugal não tinha essa mesma dimensão e relevância para os artistas brasileiros. Dito isso, é importante destacar que essa clientela imigrante era composta, em grande parte, por uma burguesia comerciante, algumas das vezes com um passado envolvido com a agricultura e o campo. Conhecidos em Portugal como "brasileiros de torna-viagem", esse grupo imigrante enriquecido encontrava na filantropia e no colecionismo de arte vias para atestar sua ascensão econômica e social. Essas eram, fundamentalmente, as características de grande parte público que o pintor português José Vital Branco Malhoa (1855-1933) encontrou tanto no Brasil, quanto em Portugal.

Ademais, entendo que a composição social da clientela é um dos principais aspectos por meio do qual é possível produzir uma aproximação comparativa entre a obra e trajetória de Malhoa às do brasileiro José Ferraz de Almeida Júnior (1850-1899), dado que o pintor brasileiro sempre foi próximo de grandes proprietários rurais de São Paulo que ao longo dessas décadas finais do século deslocam-se paulatinamente para a cidade. Associo, em grande medida (mas não apenas), a esse público e a suas expectativas o aprofundamento da exploração das temáticas e personagens do universo rural desempenhado pelos dois artistas em momento coincidente. As novas elites em processo de autoafirmação nos dois países, na medida em que crescem em poder político e econômico vão carregando consigo a conformação de um novo padrão de gosto.

4 Ver FERREIRA, 2007. 
Ou seja, é notório que, em dado momento do final do século, tanto Malhoa quanto Almeida Júnior conquistaram consagração profissional na medida em que construíram para si um público apreciador e consumidor variado em um período de transições (política, estética, econômica, etc.). No entanto, para além das encomendas (em geral retratos, principal fonte de renda), importa-nos aquilo que ambos puderam intuir muito sagazmente sobre as demandas simbólicas de sua clientela e crítica. E é nesse aspecto que emerge a hipótese de que, guardadas as especificidades locais de cada caso, ambos adquirem posições consideravelmente semelhantes nas configurações de seus respectivos universos artísticos nacionais. Além de uma clientela em similares condições econômicas, parte da qual recém-dotada de títulos de nobreza, e parte em boa proporção republicana, Malhoa e Almeida Júnior, antes mesmo da virada do século, haviam conquistado reconhecimento da crítica de periódicos, muitas das vezes enaltecidos segundo os mesmos critérios de apreciação de suas obras e atributos pessoais.

Itu, Rio, Paris, São Paulo

Para avançar a comparação, convém tratar individual e pormenorizadamente as duas trajetórias. E no polo brasileiro da análise, o foco recai sobre São Paulo e sua elite agrária que, ao longo do século, havia acumulado recursos com a produção de cana-de-açúcar e com a exportação de café.

Para melhor compreender então como se constrói a vinculação entre o artista e essa elite provinciana devemos primeiro remeter à sua origem social. Foi justamente a partir de suas relações de proximidade e compadrio com agentes locais de sua cidade natal, Itu, que ele pôde dar início à sua profissionalização no Rio de Janeiro. Foi justamente com o intermédio do pároco Miguel Correa Pacheco e o auxílio financeiro continuado de Antônio de Queiroz Telles, o Barão de Jundiaí, que Almeida Júnior conseguiu realizar sua formação completa na Academia Imperial de Belas Artes no Rio de Janeiro entre 1869 e $1874^{5}$.

Durante esse período de estudos, a imprensa paulista foi repercutindo seu desempenho em notas esporádicas. Ou seja, mesmo sem nem ainda estar formado, sua imagem como artista ligado a São Paulo foi sendo aos poucos publicamente construída. Ao final de seus estudos na AIBA, Almeida Júnior decide não concorrer ao prêmio de viagem ao exterior e em 1875 retorna a São Paulo. Essa é sua primeira tomada de posição notável no campo artístico em formatação, naquele momen-

5 Ver LOURENÇO, 1980. 
to quase exclusivamente carioca. Não permanecer no Rio de Janeiro era uma decisão em diversos sentidos polêmica para um artista brasileiro daquele período. Assim, Almeida Júnior anunciou com suas estratégias profissionais transformações relevantes mais amplas nas possibilidades de construção de trajetórias artísticas.

Com efeito, não é difícil compreender a escolha do artista de retornar para o seio do grupo que foi seu mecenas e mantenedor. É totalmente lícito afirmar que Almeida Júnior tenha retornado para onde acreditava que pudesse constituir uma clientela. Em 1876, contudo, Almeida Júnior parte para Paris com auxílio direto do imperador D. Pedro II, onde permanece até 1882. Nesse período, o processo de elaboração pública de sua biografia se acentua. Sua visibilidade cresce al imentada pelo esforço entusiasta de alguns intelectuais do interior paulista. Em 1877, por exemplo, Tristão Mariano da Costa produz o primeiro registro biográfico sobre o artista e publica no Almanach Litterario de São Paulo. Ainda em 1878, Cesário Motta Júnior (membro destacado dessa fração da elite que, entre outras coisas, havia ajudado a fundar o Partido Republicano Paulista em 1873) publica no jornal Imprensa Ytuana artigo intitulado “Um paulista distinto”, em que saúda o artista por uma premiação em Paris.

Porsua parte, nesses seis anos Almeida Júnior permaneceu de diversos modos ligado às elites paulistas. Foi nesse período, por exemplo, que o pintor muito provavelmente integrou o círculo de artistas e intelectuais centralizado por Eduardo Prado em Paris, espaço também frequentado por alguns jovens pintores naturalistas portugueses, e sobretudo por intelectuais muito próximos do anfitrião, tais como o crítico Ramalho Ortigão e o romancista Eça de Queirós ${ }^{6}$. Se o apartamento de Eduardo Prado era o centro disso que Migliaccio chamou de "comunidade cultural luso-brasileira", é relevante notar como ele opera como ponte que conecta agentes e ideias entre esses distintos universos nacionais. É também por meio dele que as ideias racialistas portuguesas ligadas à Geração de 1870 passam a integrar o debate brasileiro e o pensamento de Eduardo.

Membro da tradicional família Prado (enriquecida pelas atividades rurais mas que então enveredaria também pela imprensa), Eduardo circulou intensamente entre São Paulo, Rio de Janeiro, Lisboa e Paris. Aqui há que se destacar da atividade intelectual de Eduardo Prado sua adesão

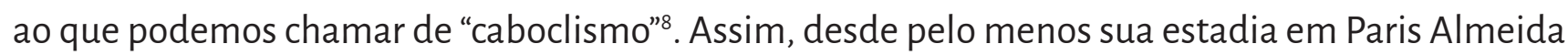
Júnior trava contato com ideias, imagens e teorias que enquadram o homem do campo em viés na-

\footnotetext{
6 MIGLIACCIO, 2014, p.267

7 Idem, p.266.

8 Ver BERRIEL, 1997.
} 
cionalista. Cabe lembrar que foi também nesse período que esboça seu primeiro quadro com essa temática, "Derrubador brasileiro", de 1871.

No entanto, foi sobretudo a partir de seu regresso ao Brasil que seus vínculos com os projetos político-culturais da elite paulista se aprofundaram. Com o acúmulo de prestígio conquistado pela estadia em Paris, as encomendas aumentaram e variaram. E foi justamente na década final do século XIX que Almeida ]únior vai fazer a maior parte dos seus quadros ditos regionalistas. Segundo Fernanda Pitta "Almeida Júnior passaria a ter nessa década um público de colecionadores para seus trabalhos, que compra com mais assiduidade paisagens e cenas de gênero, em maior número do que nas décadas anteriores, e não só principalmente retratos" ${ }^{\text {. }}$ Essa era a resposta pictórica que ele vinha produzindo tanto em função dos estímulos provenientes de convenções estéticas em voga e que circulavam, quanto das expectativas de uma clientela que ele conhecia bastante bem.

Da desilusão à circulação internacional de Malhoa

Malhoa, por sua vez, embora partisse de uma posição econômica familiar muito similar à de Almeida Júnior, é preciso destacar que não possuía nenhum tipo de mecenas. Foi em um ateliê que, como aprendiz, aproximou-se pela primeira vez da arte e recebeu os incentivos de seu mentor, Leandro Braga (1839-1897), para seguir estudos. A menção ao entalhador como primeiro mestre de Malhoa não deve ser algo de cunho meramente ilustrativo. Braga foi discípulo do escultor francês Célestin Calmels, com quem colaborou na execução do Arco Triunfal da Praça do Comércio, em Lisboa. Tornou-se um reconhecido entalhador na segunda metade do séc. XIX. Trabalhou, por exemplo, em decorações para a realeza e em palacetes da aristocracia portuguesa ${ }^{10}$. Malhoa foi aluno de Braga por pouco mais de um ano, quando o entalhador sugeriu que o aluno tentasse carreira artística na Academia Real de Belas Artes de Lisboa (ARBA). No entanto, suas relações com o mestre permaneceram, já que Braga manteve-se próximo dos artistas do Grupo do Leão.

Em 1869, então, Malhoa foi definitivamente aceito na ARBA, tendo ali permanecido até 1875 (período coincidente ao que Almeida Júnior passou na AIBA). Experimentou já nesse período a pintura ao ar livre, estimulado por Tomás da Anunciação. Pelo lado português, a temática rural não era absolutamente nova, já que foi constante nas obras de pintores do romantismo. Portugal incorpo- 
rou cedo artistas que valorizavam a representação de paisagens rurais e cenas populares. Desse período, seus primeiros estudos são paisagens (rochedos e matas dos arredores de sua cidade natal, Caldas da Rainha), mas realiza também alguns trabalhos animalistas no final da década de 1870, quando esboça também seus primeiros registros na pintura de gênero.

No entanto, o triênio final de sua formação é marcado por frustrações. Malhoa concorreu por duas vezes ao prêmio de viagem ao exterior e não foi premiado. Após a segunda tentativa frustrada na categoria de Paisagem, afastou-se da academia ${ }^{11}$. É importante, então, termos em conta que Malhoa não estudou no exterior. Não agregou ao seu processo de consagração um período nas academias internacionais, grandes instâncias de consagração. E sabia bem o que isso poderia significar para suas pretensões artísticas. O fato atua em sua trajetória como um marco de reorientação de estratégias. Malhoa principia então por internacionalizar sua arte nas margens do campo artístico transnacional. Em 79 expõe pela primeira vez no Rio de Janeiro e somente no ano seguinte expõe pela primeira vez no salão da Sociedade Promotora de Belas Artes, em Lisboa. Ainda em 1881 expõe em Madri e é somente no final dos anos 1890, depois de todo um percurso de acumulação simbólica, é que passou a expôr nos Salons em Paris.

Ao contrário do que se poderia esperar, não ter conseguido estudar em Paris acabou tornando-se uma espécie de trunfo na conformação de sua identidade artística. Além do mais, ter-se mantido inserido no círculo lisboeta de artistas ditos "modernos" foi também fundamental para os rumos que sua trajetória adquiriu. Malhoa esteve na gênese do Grupo do Leão, formado por jovens artistas inconformes com a situação artística em Portugal. A partir de 1881 ele passa a expôr nas Exposições de Quadros Modernos, organizadas pelo grupo.

Malhoa e sua geração de colegas artistas foram logo bem recebidos pela crítica e aos poucos protagonizaram o cenário da produção artística em Portugal. Sobre Malhoa, a despeito de alguns notáveis apontamentos negativos ao longo da década de 1880, a crítica, principalmente a partir da década seguinte e século XX a dentro passa a exaltá-lo como o "emoldurador da raça"12, "um artista bem nacional"13 e outras expressões que lhe atribuíam a extrema capacidade de exprimir o nacional por meio da arte. Assim também a crítica foi contribuindo decisivamente para a produção do valor artístico das obras.

Livre do temido "estrangeiramento", é nesse aspecto que Malhoa teve sua originalidade re-

\footnotetext{
11 Ver MONTÊS, 1959.

12 PINTO, 1934.

13 ARTHUR, 1903, p.307.
} 
conhecida. E se até então os grandes colecionadores em Portugal consumiam majoritariamente arte estrangeira, os novos colecionadores, em grande parte oriundos do interior do país, tais como José Relvas e o Dr. Anastácio Conçalves, foram desenvolvendo o gosto pelo naturalismo nacional. Foi sobretudo dessa burguesia ascendente de médicos, advogados e lavradores, majoritariamente republicana, que Malhoa esteve próximo. Ele fez dela sua clientela e seu grupo de sociabilidade.

Por vias diferentes, Malhoa e Almeida Júnior atingiram lugares similares, alocados na posição de "pintores nacionais". Se um foi considerado legitimamente português por não ter ido a Paris, o outro manteve-se brasileiro (e, sobretudo, paulista) apesar de lá ter ido. Com um pé nos meios dissidentes, próximos à crítica antiacadêmica, e outro ainda nos espaços expositivos e visíveis das academias, não é fortuito que ambos tenham orbitado entre tradição e inovação. Em diversos momentos foram capazes de mobilizar a tradição de que eram tributários para constituírem projetos estéticos afinados ao gosto e às pretensões dos grupos social e politicamente emergentes. Capazes de satisfazer parte significativa da clientela, souberam se constituir como importantes agentes culturais cuja consagração, em dado momento, Ihes garantiu ampla capacidade de circulação e alguma margem de experimentação. 


\section{Referências Bibliográficas}

ARTHUR, Ribeiro. Arte e Artistas Contemporâneos. Vol. III, Lisboa : Livraria Moderna, 3a Série, 1903.

BERRIEL, Carlos E. O. Tietê, Tejo, Sena. A obra de Paulo Prado. Tese de Doutorado apresentada ao Departamento de Teoria Literária do Instituto de Estudos da Linguagem da Unicamp. Campinas, SP, 1994.

BRACA, P. B. Leandro Braga e as artes decorativas 1839-1897. Catálogo, Lisboa: Instituto de Comunicação Social, 1997.

DAZZI, Camila. "O moderno no Brasil ao final do século 19". in: Revista de História da Arte e Arqueologia. No.17, Jan/Jun 2012, Campinas, SP, pp. 87-124.

FERREIRA, Antonio C. A epopéia bandeirante: letrados, instituições, invenção histórica (1870-1940). São Paulo: Editora UNESP, 2002.

FERREIRA, Marie-Jo. Os portugueses do Brasil, atores das relações luso-brasileiras, fim do século XIX-início do século XX. Rio de Janeiro: Arquivo da Cidade do Rio de Janeiro, 2007.

FRANÇA, José Augusto. Arte em Portugal no século XIX. Lisboa: Bertrand, 1966 vol.2.

"A figura do camponês em artes e letras do oitocentos". In: Revista Crítica de Ciências Sociais, No. 7/8, Dez. 1981, pp. 101-109.

LOURENÇO, Maria Cecilia França. Revendo Almeida Júnior. 2 vols. Dissertação de Mestrado. São Paulo: Escola de Comunicações e Artes, USP, 1980.

MICLIACCIO, L. "Entre Lisboa, Paris e Rio de Janeiro. Para o estudo das relações artísticas entre Portugal e o Brasil na segunda metade do século XIX", in: Oitocentos - Tomo III : Intercâmbios culturais entre Brasil e Portugal. $2^{\text {a }}$. Edição / Valle, A; Dazzi, C. e Portella, I. (Orgs.). Rio de Janeiro: CEFET/R], 2014, pp. 265-279.

"Notas para um inventário de obras de arte portuguesas em coleções brasileiras", in: II Congresso Internacional de História da Arte. Portugal: encruzilhada de culturas, das artes e das sensibilidades. Lisboa: Almedina, 2001.

MONTÊS, António. Malhôa. Caldas da Rainha : Museu José Malhoa, 1959.

PINTO, Manuel de Sousa (1934), Últimos Anos de Malhoa, Caldas da Rainha: Tip. Caldense.

PITTA, Fernanda M. "Um povo paca to e bucólico": costume, história e imaginário na pintura de Almeida Junior. Tese de Doutorado, São Paulo, ECA-USP, 2013.

SALDANHA, Nuno. José Vital Branco Malhoa - O pintor, o mestre e a obra. Tese de Doutoramento em História da Arte, Universidade Católica Portuguesa, Lisboa: FCH/UCP, 2007.

SILVA, Maria do C. C. "A arte francesa na crítica de José Duarte Ramalho Ortigão e de Mariano Pina". In: Anais do III Colóquio de Teoria, Crítica e História da Arte. Instituto de Artes, Universidade de Brasília, 2019, pp. 19-27.

VALLE, Arthur. "Considerações sobre o Acervo de Pintura Portuguesa da Pinacoteca da Escola Nacional de Belas Artes". 19\&20, Rio de Janeiro, v. VII, 2012.

"A ‘Exposição de Arte Portuguesa" no Rio de Janeiro em 1902 e sua recepção". In: Revista de História e Estudos Culturais, Vol. 12, Ano XII, no.1, 2015. 